\title{
FIBROCYSTIC DISEASE OF THE PANCREAS IN AN ADOLESCENT WITH MINIMAL PULMONARY INVOLVEMENT
}

\author{
BY \\ R. C. KING \\ From St. Bartholomen's Hospital, London
}

(RECEIVED FOR PUBLICATION MARCH 20, 1956)

Fibrocystic disease of the pancreas is a congenital condition seen most frequently in infancy and early childhood, resulting from the production of excessively viscid mucus in the alimentary and respiratory tracts. It may present within the first few days of life as acute intestinal obstruction, resulting from meconium ileus, and is characterized clinically in later infancy and childhood by steatorrhoea, retarded growth, progressive bronchiectasis and pulmonary fibrosis and, on occasions, cirrhosis of the liver. Two unusual but probably related features make the present case worth recording, namely, the healthy survival of the patient to his present age (16 years) together with the minimal involvement of the respiratory system.

\section{Case Report}

R.B. was born at full term of a mildly toxaemic

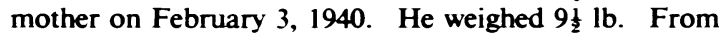
birth his bowels were opened up to 10 times daily with the passage of bulky, offensive, greasy stools and for the first four months his weight fluctuated between 71 and $9 \frac{1}{2} \mathrm{lb}$. Thereafter it slowly increased. At 1 year he had measles complicated by rectal prolapse, and at the age of 2 he was admitted to the Middlesex Hospital for investigation of steatorrhoea. Stool analysis at that time revealed $49 \cdot 4^{\circ}$ fat content, of which $45 \cdot 1^{\circ}$ o was unsplit, while microscopy showed numbers of undigested meat fibres with many starch granules. Treatment with a low-fat diet was instituted but the bowel symptoms remained unaltered. Apart from two episodes of pneumonia and a recurrent winter cough, he remained well, although under weight, until his admission to St. Bartholomew's Hospital on July 12, 1954, with a 24-hour history of intermittent severe colicky lower abdominal pain. He had vomited on four occasions but his bowels had been opened only twice, the stools being of much smaller volume than normal and containing no blood. There was no relevant family history: his mother and younger sister were well, although his father suffered from epilepsy.

On examination he was under weight for his age : height $5 \mathrm{ft}$., weight 5 stone $9 \frac{1}{1} \mathrm{lb}$. There were no secondary sex characteristics and the testes and penis were small. He was flushed and anxious with a temperature of $99 \cdot 4^{-} F$., pulse rate 130 , respirations 24 . The tongue was furred, the heart and lungs appeared healthy but there was well marked clubbing. The abdomen was not distended. Peristaltic waves were visible to the left of the umbilicus, and in the right iliac fossa there was a mobile, sausage-shaped mass which was acutely tender on pressure. Rectal examination was normal. A diagnosis of intussusception was made, and the symptoms and signs resolved within 12 hours. Investigations were then begun to elucidate the nature of the steatorrhoea, with the following results:

Haemoglobin $96^{\circ}$ (Haldane): white blood count 7,000 per c.mm. (differential count normal); E.S.R. $6 \mathrm{~mm}$. in one hour (Westergren): urine, no albumin or sugar; serum calcium $10.5 \mathrm{mg}$. per $100 \mathrm{ml}$.; serum inorganic phosphate, $3.8 \mathrm{mg}$. per $100 \mathrm{ml}$ : plasma proteins, albumin $4.6 \mathrm{~g}$. per $100 \mathrm{ml}$. and globulin $1.8 \mathrm{~g}$. per $100 \mathrm{ml}$.

The serum antithrombin level was normal (MacFarlane's technique).

A glucose tolerance test gave a fasting blood sugar of $88 \mathrm{mg}$. ${ }^{\circ}$, and after $50 \mathrm{~g}$. dextrose, $94 \mathrm{mg}$. (1 $\frac{1}{2}$ hour), $103 \mathrm{mg}$. ${ }^{\circ}$ (one hour), $88 \mathrm{mg}$. ${ }^{\circ}$ ( $\left(1 \frac{1}{2}\right.$ hours), $69 \mathrm{mg}$. ${ }^{\circ}$ o (two hours).

Stool microscopy showed large numbers of undigested and partially digested muscle fibres. A fat balance over four days gave $68^{\circ}$ absorption.

Duodenal intubation showed on two occasions yellow viscous alkaline juice, but no tryptic activity could be detected by the Horsfield method.

The sputum was yellowish green and mucopurulent. Culture yielded a mixed growth of Staph. pyogenes and Haemophilus influenzae.

The Mantoux test was negative to 1 in 100 .

A radiograph of the chest (Fig. 1) in both upper zones showed streaky linear shadowing, and on the more penetrated film there was a honeycomb appearance in the left cardiophrenic region.

On a bronchogram (Fig. 2) the bronchi on both sides appeared normal.

Both antra were opaque radiologically. 


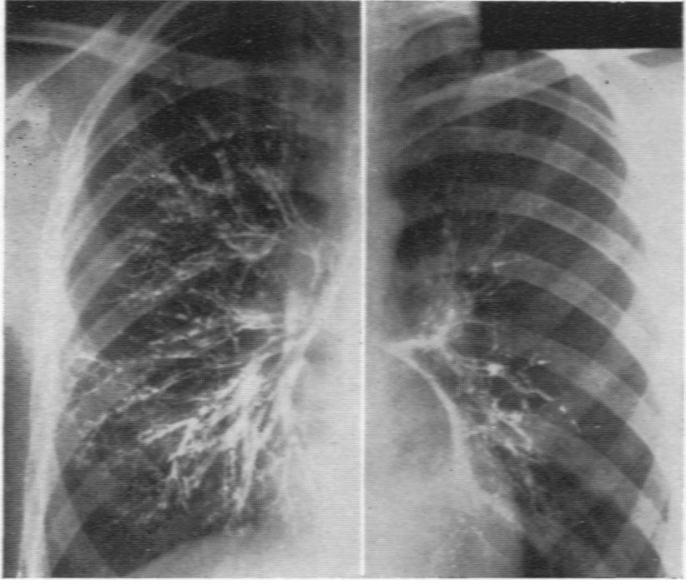

FIG. 2.-The normal bronchogram.

On a barium follow-through the jejunum appeared normal, but the ileum was dilated and contained excess gas. There was poor coating of the mucosa by the barium consistent with the presence of excess fat. Similar changes were seen in the colon, which was rather dilated.

A diagnosis of fibrocystic disease of the pancreas with minimal pulmonary involvement was made. Treatment was begun with a triple strength pancreatin compound ('panteric 503", Parke Davis) grains 10 three times a day with meals. There was an immediate improvement in the frequency and character of the stools, the bowels being opened only two to three times a day and the stools being much less bulky and offensive. Over the next 12 months he gained 4 in. in height and $17 \mathrm{lb}$. in weight, but the productive cough has continued unchanged. He is now aged 16 and is working as a fulltime photographer's assistant.

\section{Discussion}

The diagnosis of fibrocystic disease was suggested by the history of steatorrhoea from birth associated with a chronic cough, while confirmation was obtained by the analysis of duodenal juice aspirated on two separate occasions. The development of intussusception has been noted before in fibrocystic disease (Norman, 1954a) and its occurrence was probably coincidental. The normal antithrombin titre is unusual but Norman (1954b) has pointed out that only $90 \%$ of children with proven fibrocystic disease show a significantly reduced level. The appearances seen on the plain radiograph of the chest, in particular the streaky linear upper zone shadowing, are suggestive of quiescent pulmonary tuberculosis. This diagnosis is, however, hardly compatible with a negative Mantoux test to a dilu-

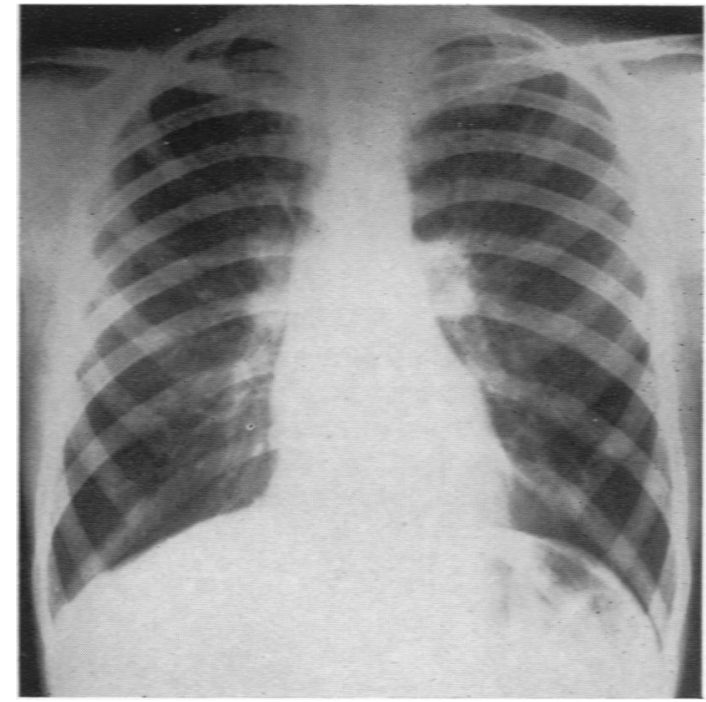

FiG. 1.-Chest radiograph showing linear upper zone shadowing and honeycomb appearance in left cardiophrenic region.

tion of $1 / 100$. It seems reasonable, therefore, to ascribe the changes to a degree of peribronchial fibrosis resulting from a chronic low-grade bronchial infection.

Although the condition has, in the past, been considered to be a disease of infancy and childhood. there are now many isolated reports of protracted survival. Parmelee (1935) collected a group of cases of which the oldest was 14 years, while Pugsley and Spence (1949) reported the survival of a patient to the age of 17 . Hendrix and Good (1956) gave a detailed account of a patient who survived to the same age, while a clinico-pathological conference (1954) on fibrocystic disease of the pancreas held at the Hammersmith Hospital was concerned with a man who died at the age of 19 years and 9 months. Even more striking was the patient described by Burnard (1953) who was able to continue his normal occupation at the age of 23 despite severe respiratory involvement and persistent abdominal symptoms. With one exception all these patients were dead and post-mortem examination had revealed the presence of gross bronchiectatic changes. Burnard's case was still alive at the age of 23 , but a bronchogram had demonstrated the presence of diffuse cylindrical bronchiectasis two years previously. Emphasis has very rightly been laid on the importance of antibiotics in the continued survival of such patients. In the case recorded here, however, antibiotics have not been used because, although the pulmonary condition is severe enough to cause a chronic productive cough 
and minimal radiological changes, it has not advanced sufficiently to produce either severe systemic symptoms or any definite bronchographic evidence of bronchiectasis. The absence of severe pulmonary involvement in a patient of this age with proven fibrocystic disease is a most unusual finding, and is undoubtedly the explanation of his continued healthy survival.

\section{Summary}

The account is given of a patient with fibrocystic disease of the pancreas whose admission to hospital was precipitated by an episode of intussusception.

Although now aged 16, the patient is living a normal healthy life with minimal respiratory or alimentary symptoms.
An unusual feature of this case is the absence of gross pulmonary changes, and it is to this that the patient's continued good health is probably due.

I am grateful to Dr. K. O. Black for permission to publish this case and to Dr. A. W. Franklin and Dr. A. P. Norman for their opinions. My thanks are also due to Dr. R. Kemp Harper for his interpretation of the radiographs and to Dr. W. G. Dangerfield for the analyses of duodenal juice.

\section{ReZERENCES}

Burnard, E. D. (1953). N.Z. med. J.., 52, 395.

Clinico-pathological Conference (1954). Postgrad. med. J.. $30,646$.

Hendrix, R. C. and Good, D. M. (1956). Ann. intern. Med., 44, 166. Norman, A. P. (1954a). Postgrad. med. J., 30, 652. (1954b). In Recent Advances in Paediatrics, ed. Gairdner, D. p. 254. London.

Parmelee, A. H. (1935). Amer. J. Dis. Child, 50, 1418.

Pugsley, H. E. and Spence, P. M. (1949). Ann. intern. Med., 30, 1262. 